\title{
Octanoic Acid
}

National Cancer Institute

\section{Source}

National Cancer Institute. Octanoic Acid. NCI Thesaurus. Code C68331.

A saturated medium-chain fatty acid with an 8-carbon backbone. Octanoic acid is found naturally in the milk of various mammals and is a minor component of coconut oil and palm kernel oil. 